\title{
AS PRÁTICAS POLÍTICAS NA ESCRITA ANTROPOLÓGICA, ETNOGRAFIA EM HIPERTEXTOS E A PRODUÇÃO DE CONHECIMENTO EM ANTROPOLOGIA ${ }^{1}$.
}

\author{
Ana Luiza Carvalho da Rocha
}

Na pesquisa que se desenvolve no Banco de Imagens de Efeitos Visuais desde 1997, no Programa de Pós-Graduação em Antropologia/UFRGS, onde se emprega a hipermídia na produção de novas escritas etnográficas, acredita-se que a introdução de novas tecnologias tem sido capaz de nos encaminhar para o aprofundamento de uma reflexão singular o estatuto da representação etnográfica no contexto da cultura visual do mundo contemporâneo e seus efeitos sobre a prática escriturística do antropólogo para a produção antropológica de conhecimento.

Assim, gostaríamos de referir esta apresentação ao processo de pesquisas com coleções etnografias escritas e a construção de etnografias hipertextuais dentro da base de dados do BIEV e a tomada de consciência que vimos experienciando da não opacidade do espaço livresco na construção dos escritos antropológicos tendo em vista a necessidade de se pensar o espaço da produção textual que configurou classicamente o livro impresso como lugar de realização da obra etnográfica.

Procuramos retornar o debate em torno da escrita etnográfica e suas artes da persuasão, tomando-se agora como tema central sua articulação com o espaço livresco, território convencionalmente estipulado para a exposição e divulgação dos fatos da ciência antropológica.

Um espaço que nasce e se banaliza com a invenção da imprensa no Ocidente moderno e que se compõe do formato da folha, retrato ou paisagem, branca ou amarelada, A4 ou A3, etc. Eis o espaço primeiro da representação da pratica escriturística etnográfica e que todo o antropólogo pode explorar tal qual um pintor explora sua tela. Pagina-tela onde dispõe seus fatos de «homens da ciência », entretanto, segundo sua adesão a um determinado estilo de escrita. Uma grafia que organiza a Antropologia como campo científico e que possui uma história como espaço de construção do Outro. Uma grafia que deve expressar o compromisso do antropólogo com a

1 Este artigo é fruto de inúmeras contribuições de bolsistas de iniciação científica CNPq e FAPERGS, bolsistas de apoio técnico CNPq e pesquisadores associados CNPq e CAPES que contribuíram ou têm contribuído, desde 1998, com o seu trabalho para a realização da pesquisa do Banco de Imagens e Efeitos Visuais, entitulada Coleções etnográficas, memória coletiva e patrimônio etnológico no corpo do Projeto Integrado de Pesquisa Estudo antropologico sobre memória coletiva, itinerários urbanos e formas de sociabilidade no mundo contemporâneo. Em especial gostaríamos de agradecer as colaborações de Rosana Pinheiro Machado, Olavo Ramalho Marques, Rafael Devos, Patricio Rodolfo, Viviane Vedana, Luciana de Mello, Rafael Derois, Paula Biazus e Vanessa Zamboni, entre outros. 
oralidade da qual emerge a figura do "nativo", e cujas palavras e frases enunciadas a partir da letra órfã, sem pai, nas folhas de um livro, devem fazer ecoar, nos ouvidos de seus leitores, a sonoridade da voz de personagens cujas histórias são atribuídas, pelo antropólogo, as situações vividas por ele e pelo seu grupo, durante um determinado espaço de tempo. Uma grafia cujo corpo da letra, muda e falante, é capaz guiar o leitor da obra na compreensão das intenções e das ações que orientam os gestos e as posturas do "nativo", extensivos aquelas de toda seu grupo de pertença, pelo engajamento que aquilo que é narrado the provoca e cujo enunciado livre ou socorrido, por uma imagem técnica, necessita ser semelhante ao que o próprio antropólogo sentiu quando em campo, entre eles, e com eles.

Tomam-se aqui os comentários de Michel De Certeau sobre a Etno-grafia, na obra Escritas da história (2002), de Jacques Rancière, sobre a voz viva e a escrita morta, em Políticas da Escrita (1995), Roger Chartier, De Leitor a Navegador, de M. Foucault, Qu'est-ce qu'un auteur? (1969) bem como dos comentários de Marc Escola sobre as obras de A. Brunn, L'Auteur (2001), de P. Bénichou, L'Écrivain et ses travaux (1967) e de Roland Barthes (1970; 1973) para pensar aqui o tema da escrita, da memória e da política na produção antropológica de conhecimento através de um percurso de imagens.

Inicialmente, caberiam algumas reflexões iniciais onde podemos situar o tema da memória, da imagem e das práticas políticas no interior do estudo da escrita na produção de conhecimento em Antropologia. Aborda-se aqui a escrita antropológica como parte de integrante de todo e quaisquer outros sistemas de escritas que fazem parte do patrimônio da humanidade, pela aliança singular que ela estabelece entre imagem presenciada e palavra ouvida pelo antropólogo; arte do visível dada nos seus signos legíveis, cuja decifração, pelo leitor, se traduz num ato de construção de sentido para o mundo que, através dela, o antropólogo desenhou. Ao mesmo tempo, para além do sentido que encerra o reconhecimento puramente visual de uma palavra, cujos elementos ideográficos estabelecem diferenças inaudíveis aos ouvidos do leitor, mas que, na sua língua, encontram uma imagem fiel, a escrita na produção antropológica de conhecimento configura-se sistema particular de escrita constituído por uma tradição de obras e de textos, todas elas portadoras de um certo número de traços temáticos e formais (situações, personagens, acontecimentos, praticas estilísticas, etc.) fundadores de discursividades. Em especial, queremos, com tais comentários, apontar para a importância de se pensar a aventura intelectual que encerra o sentido e a experiência do fazer antropológico diante dos desafios da palavra escrita, do espaço livresco e do lugar da figura do autor e do leitor para o caso do estatuto "científico" da representação etnográfica. 
Primeiramente, a escrita não é simples transcrição da palavra enunciada e anunciada; a palavra escrita é dependente do reconhecimento visual da própria ortografia e dos signos gramaticais que a constituem por parte do leitor sendo elas que nos permitem diferenciar coisas escritas de forma idênticas, mas pronunciadas da mesma forma. Para que a letra morta se tornasse falante, a escrita precisou ir além da invenção de signos discretos (o alfabeto), totalmente mudos; ela precisou se ocupar progressivamente da transcrição não apenas daquilo que era dito, para ir além das palavras, e transcrever, as inflexões, as entonações e a sonoridade da palavra-viva, ou seja, o poder criador da fala humana. Neste sentido, a invenção da pontuação e de toda a sua coreografia representou para a escrita não apenas a possibilidade de um texto adquirir uma profundidade emocional, mas também expressar sua própria respiração.

Para o caso do espaço livresco que classicamente configura toda e qualquer obra etnográfica não se pode esquecer a página que é o lugar onde os dados imediatos de campo podem ser restaurados pelo antropólogo e onde a sua função-autor desempenha papel importante na forma como ela pode ser desmembrada e articulada por segundo uma totalidade, colocando em destaque sua forma pela técnica da "montagem", por exemplo, na forma de um diário intimo, de cartas, etc. Nesse sentido, cabe se perguntar como o dispositivo livro se torna o espaço diegético de exercício da função-autor no campo da produção de conhecimento em Antropologia, em suas aproximações e distâncias com o espaço ficcional no qual circula o corpo da letra muda e falante do antropólogo-narrador.

Neste sentido, gostaríamos desenvolver a idéia de que os imperativos da distribuição da letra morta e falante no texto, no interior do espaço livresco, sua distribuição na superfície da pagina, com instrumentos que lhe permitem identificação, paginação, numerações, etc., aos quais esta submetida a toda a obra antropológica escrita, podem significar aspectos significativos para a compreensão dos caminhos tortuosos que ela realiza para expressar os aspectos efêmeros, voláteis e vivos dos fenômenos culturais por ela expressos.

\section{As condições de produção de conhecimento em Antropologia, remontando os estudos de literatura aplicados a escrita do pensamento antropológico}

Lembrando a obra celebre de C. GEERTZ (2002) sobre a figura do antropólogo como autor e a polêmica dos pós-modernos, o estudo sobre a intertextualidade em literatura pode ser aqui sugestivo para se recolocar aqui o caso do estudo da filiação da escrita realista do texto etnográfico a figura do narrador-autor nos relatos de viagem, ou ainda a influencia sofrida por esta modalidade de escrita etnográfica da tradição narrativa do romance moderno do qual resultaria a 
preocupação dos pais fundadores da Antropologia com a "verdade" dos dados etnográficos e da sua sustentação, em termos metodológicos, no interior deste campo disciplinar.

Da mesma forma, uma reflexão mais acurada sobre os laços simbólicos que unem sujeito do autor a escrita, no sentido de ser e estar assujeitado por sua matéria, nos termos de J. RANCIÈRE ( 1995 ), a letra órfã, muda e falante, pode ser aqui sugestiva para a desconstrução do autor, da autoria e da autoridade etnográfica na produção escrita antropológica. Nem a pessoa do autor é totalmente o "sujeito" de sua escrita, nem a matéria humana da qual sua obra trata é seu mero objeto tanto quanto é sujeito de uma verdade, própria a si-mesma, reconhecida como tal. O tema da autoridade etnográfica não trata apenas dos problemas subjetivos que cercam a escrita antropológica na produção do rigor cientifico de suas afirmas em relação as culturas e sociedades que são seu objeto de estudo. $\mathrm{O}$ debate em torno do tema da autoridade etnográfica remete a que se reflita sobre a presença da figura do autor, mas exige que se supere a idéia de que ser trata de um tema apenas circunscrito as discussões sobre lugar do antropólogo-autor segundo determinadas modalidades construção narrativa, melhores ou piores, a partir das quais ele estaria autorizado, ou não, a assinar seu nome sobre uma determinada cultura.

Assim, o debate em torno da autoridade da representação etnográfica nas políticas de escrita em Antropologia só adquire sentido no interior de uma tradição escrita, referida a gêneros e formas, e cuja originalidade, paradoxalmente, no passado, no presente e, mesmo, no futuro, só pode ser apreciada em relação as suas fontes; ela esta referida a procedimentos decodificados que lhe atribuem, inclusive, valor de documento histórico. Não se lê a produção escrita de conhecimento em Antropologia como quem lê um texto literário, mas como quem reconhece nela um documento histórico, pois ela esta estreitamente vinculada à série de acontecimentos de sua produção, ou sejam ao trabalho de campo, sendo sempre parte irredutível deste. Isto nos conduz a outros 3 outros aspectos fundamentais até certo ponto pouco ressaltados do debate entre modernos e pós-modernos em Antropologia: 1) o antropólogo só realmente se torna sujeito de verdade na sua produção textual através da matéria que é própria a escrita, isto é na medida em que a verdade que ela inscreve traz a marca do próprio do antropólogo naquilo que ela descreve como tendo existindo enquanto realidade para ele; 2) a escrita antropológica, para além do reconhecimento de seu status cientifico, possui um destino estético por ser estar contida no interior de uma obra que tem por finalidade produzir modificações subjetivas no seu leitor ; 3) a composição dos escritos dos antropólogos, não foge a regra de outras formas de escrita, pois está povoada das leituras de outras obras (poesia, filmes, romances, sons, etc.) de sua tradição cultural e, da mesma forma, pela necessária vinculação com o seu caráter etno-grafico, esta habitada por lembranças dos fatos e dos acontecimentos compartilhados em campo com o grupo pesquisado. 
Portanto, e na perspectiva da intertextualidade, é quase impossível se operar com a idéia de autor e da "fuga do real" nos escritos antropológicos. Neste ponto, a recusa à ilusão referencial da escrita etnográfica pelo fato de ela não ter referência ao mundo real, mas estar referida ao mundo da literatura, seria, na perspectiva da intertextualidade, absurda, pois o texto e o mundo não podem ser separados, mesmo para o caso da obra etnográfica que não é uma exceção. Adotando-se os comentários de RIFATERRE (1979, 29-33) sobre a intertextualidade como fenômeno que se contrapõe à ilusão referencial, para o caso da escrita poética que preside a construção de todo texto literário ou não, pode-se considerar que a autoridade do texto etnográfico esteve longo tempo referida a capacidade desta escrita "reter" o real. O uso da técnica do diário de campo como um dos momentos cruciais do antropólogo depurar a significação da retórica das suas palavras na descrição da cultura do Outro, e o seu lugar no processo de operação textual em antropologia é aqui paradigmático. Pensado a gênese da produção escrita em Antropologia não se pode deixar de perceber a relação entre a matéria transmitida pelas suas obras clássicas e suas influências em termos dos atos complementares que elas abraçam, ou seja, a herança e a invenção de praticas de escritas.

Assim, a referencia dos gêneros de escrita antropológica ao mundo do romance tanto quanto ao dos relatos de viagem podem provocar, nos dias atuais, em todo o aprendiz de antropólogo a salutar reflexão sobre a ilusão da equivalência direta e literal da escrita etnográfica ao mundo da sua experiência real em campo.

O reconhecimento desta tradição de escrita no interior da produção de conhecimento em Antropologia torna rica a análise das influências de tudo aquilo que está fora tout court da etnografia, por exemplo, o mundo livresco e seus gêneros de escrita, precisamente quando de percebe ser este o fenômeno que permitiu a própria existência da figura do antropólogo existir como tal, hoje. Perde-se, sem dúvida, a ilusão romântica da validade cientifica da tecnologia da escrita, ancorada na figura do autor e do seu poder absoluto de criação e na crença da opacidade do dispositivo da escrita como capaz de dotar de neutralidade o pensamento antropológico. Por outro lado, ganha-se com o poder da escrita precisamente pelo fato de, através dela, a representação etnográfica não aderir ao fluxo da experiência real do antropólogo com um determinado grupo social, num determinado tempo e espaço. No reconhecimento de uma tradição, a escrita antropológica rompe com o ilusionismo da unidade imediata da escrita antropológica que a filia a unidade entre a voz e o corpo do antropólogo em campo; e mais ainda, com a ilusão desta unidade a uma outra, a unidade entre a voz e o corpo das culturas e sociedades por ele estudada, descritas na imediata unidade das vozes e dos corpos de seus indivíduos e/ou 
grupos. E que ele busca restaurar ao mundo do leito através de seus escritos. Ao se romper, na escrita antropológica, esta unidade imediata entre a voz-fala individual do antropólogo-autor e a voz da cultura e sociedade por ele estudada, manifesta-se, finalmente, o caráter ético de sua escrita. Desfeita a unidade imediatista da escrita com aquilo que ela descreve, interpreta, traduz ou compreender a produção de conhecimento antropológica acaba por situar-se no interior dos modos de produzir conhecimento próprio à civilização da escrita (que é lhe peculiar e inerente, mas que é de sua propriedade).

Fica claro aqui os limites da polêmica instaurada pela Antropologia pós-modernos, principalmente entre os mais adeptos da antropologia textualista ${ }^{2}$, em seus comentários sobre as relações intertextuais que configuram a narrativa etnográfica terem sido ofuscadas pelo busca do ponto de vista da antropologia realista/interpretativista. Em especial para alguns destes antropólogos, é na recusa de se pensar a operação textual que produz o texto etnográfico que se perde a sua qualidade autoral, sendo que um tal texto deveria retratar os aspectos situacionais e dialógicos dos antropólogos com o grupo pesquisado através da produção de novas formas de escrita (como se isto embora encoberto na superfície da escrita, ali não estivesse presente). Sob este aspecto, para alguns deles, a unidade textual da obra etnográfica residira no seu caráter alusivo ou remanescente do contexto etnográfico (alegórico, nos termos de J. CLIFFORD,1999), onde o uso apropriado de palavras pelo etnógrafo para designar os fenômenos culturais deveria guardar o sentido da "coisa etnografada" pela via da racionalização de todos os processos simbólicos e metafóricos que a linguagem escrita contempla.

Entretanto, seja para o caso da antropologia realista/interpretativista, seja o caso da antropologia textualista aqui mencionada, o tema do percurso intertextual que produz a escrita antropológica como condição do pensamento antropológico conduzir suas investidas interpretativas dos sistemas culturais a um ponto comum, não se fez fecundo como poderia ter sido uma tal controversa. Longe da "prosa do mundo racional" e do universo heróico dos antropólogos "realistas", o corpo da letra na polêmica entre pós-modernos e interpretativistas continua cindindo numa discussão prosaica sobre a ficção ou da produção escrita em Antropologia. Nos termos de J. RANCIÈRE (1995), a perturbação da escrita, tão bem detalhada nos estudos de A. LEROIGOUHRAN sobre a linguagem dos símbolos que encerra arqueologia da escrita nas sociedades humanas, $\mathrm{O}$ gesto e a palavra, se coloca fora da produção de conhecimento em Antropologia, como como se fosse possível realizar este procedimento de dissecação no interior do próprio

\footnotetext{
${ }^{2}$ Emprega-se aqui algumas categorias analíticas retiradas da obra de P. RABINOW, Antropologia da Razão, Rio de Janeiro, Ed. Relume-Dumará, 1999, em especial, o capítulo Representações são fatos sociais : modernidade e posmodernidade em Antropologia
} 
se o pensamento antropológico pudesse se estar acima de qualquer suspeita numa tentativa de separar o que é "exterior" ao enunciado do que lhe é "interior" autor, separando-o de sua obra, e, finalmente, ignorando os laços que a unem aos seus leitores pela dificuldade em aceitar a disjunção entre o logos vivo e a letra-morta.

Com isto os antropólogos "pós-modernos" tanto quanto os interpretativistas encontram-se, em ambos os casos, às voltas com o debate sobre os limites de a operação textual antropológica contemplar o mundo real, isto é, as semelhanças ou as similitudes da escrita etnográfica contemplar a coisa por ela representada. Desde ai, se perpetua o julgamento ou avaliação da escrita etnográfica e da autoridade antropológica em função apenas da exterioridade do texto que produz, o sentido do que é por ele narrado e ao mundo do autor em comparação com a experiência direta vivida pelo antropólogo junto ao seu grupo pesquisado, ainda que se reconheça, para se sair deste dilema, que, cada vez mais, ambos os lados que se encontram situados encontro etnográfico não ocupam o mesmo lugar no mundo. Trata-se não só de se considerar a referencia textual da escrita antropológica a referencia ao mundo que ela busca retratar e ao autor que a produz, nem apenas de se refletir sobre o fato de que as produções textuais do conhecimento antropológico resultam de uma tradição, isto é, da interação do antropólogo-autor com produções textuais, num eixo logico-temporal, realizadas no interior de uma comunidade de linguagem - a dos próprios antropólogos.

Se tivermos que falar aqui das práticas políticas que influenciam as escritas antropológicas, então, poderíamos traduzir nossas inquietações sobre o campo dos saberes e fazeres em Antropologia ao que J RANCIÈRE (1995) denominou a letra órfã, sem pai, na busca seu corpo de verdade. A produção escrita, hoje em Antropologia esta cada vez mais marcada pela tentativa dos antropólogos em dar corpo as suas palavras no espaço delimitado por seus escritos impressos ou manuscritos.

Para se avançar nas operações textuais que conformam a escrita antropológica torna-se necessário, portanto, refletir sobre a função não só do antropólogo-autor, mas do antropólogo leitor e de todo o seu trabalho hermenêutico de interpretação da obra etnográfica. No caso da pesquisa realizada no BIEV com a produção/criação de narrativas etnográficas hipertextuais através do suporte das novas redes eletrônicas e digitais, este desafio se torna evidente pelo fato delas não se tornarem legíveis em sua referência ao espaço livresco, mas ao espaço da Internet, fora, portanto, de seu contexto de origem. Ao contrário da tradição da cultura do papel, a produção escrita no espaço do hipertexto para ser lida pelo leitor-navegador não pode prescindir dos quadros de sua descontextualização pela via dos seus textos fundadores. Isto porque, na medida em que o apelo do texto etnográfico ao real, nas operações textuais tradicionais dos 
escritos antropológicos, sob o suporte objeto-livro, tende a isolar o leitor ordinário das significações da suas distintas tradições escritas nele contidas, na criação de novas escritas com base na textualidade eletrônica, o antropólogo precisa estar atento à sua referencialidade, ao que é próprio da letra-morta, muda e falante, para que leitor se torne igualmente seu autor-intérprete, numa posição de enunciação indeterminada.

Poderíamos aqui, portanto, parafrasear Jean ROUCH afirmando que a verdade da escrita etnográfica habita os desafios da escrita da verdade etnográfica. Logo, não se sustentaria aqui nenhuma possibilidade de uma Verdade etnográfica absoluta, mas de verdades, cada uma tendo o corpo da letra dos escritos antropológicos relacionados a própria experiência do etnográfico com o grupo por ele investigado e da qual resulta a sua/deles/nossa obra.

\section{A produção de conhecimento escrita em Antropologia e a tradição cultural do espaço livresco}

Ciência ou literatura, a produção de textos em antropologia não pode prescindir, até o momento, do espaço livresco como lugar de produção e reprodução de seu conhecimento. Moderna ou pós-moderna a produção de conhecimento em Antropologia apóia-se no espaço livresco e nos seus espaços de narração (pre-facio, e avant-propos seja dos pos-facio, notas, avisos, etc), tanto quanto em seus modos textuais como lugar de delimitação da autoridade etnográfica e da função-autor do antropólogo.

Neste contexto, as divisões de um texto originalmente produzido pelos antropólogos e a decisão, pelo editor, da sua forma de publicação em partes ou capítulos, por exemplo, tratam aqui dos mesmos problemas que vimos discutindo até o momento; não por acaso, estas questões foram ignoradas pelos antropólogos preocupados na produção intelectual antropológica a com polêmica autoridade etnográfica contida nos escritos antropológicos. O título e o design da página de um livro impresso ou de uma tese ou dissertação se apresentam como uma espécie de "fragmento-convite" ao olhar etnográfico do antropólogo e tem suas peculiaridades em ternos do consumo cultural que encerram. Elas convidam o leitor a adentrar o texto etnográfico para ler na palavra escritas as coisas que ele não sabe, nem mesmo viveu. A forma que adquire o corpo da letra na produção intelectual da literatura antropológica traz consigo as primeiras formas de interação do antropólogo-escritor com o leitor, sendo, portanto, agentes textuais que possuem um caráter de anunciação. Ainda que a leitura da letra morta, que traga vida às coisas lidas, vale lembrar a inquietação que a escrita estabelece na prática etnográfica decorre precisamente do fato de as práticas rituais compartilhadas na experiência do trabalho de campo não são as mesmas quando são adotam da forma escrita antropológica. Entretanto, pensar o espaço livresco 
na produção da escrita antropológica, lembrando R. CHARTIER (1996), é condição para que se reflita sobre o outro lado desta produção, ou seja, as condições de possibilidade de sua leitura.

Textos construídos a partir de longos parágrafos, destinado a um publico mais selecionado e erudito que textos composto de parágrafos pequenos, mais descontínuo; a simbologia do grafismo (signos abertos e fechados como pontos de interrogação, de exclamação, de suspensão; signos lógicos como virgulas, dois pontos, ponto-e-virgula; signos de marcas seqüenciais, como parênteses, aspas, etc.) traduzem uma maneira de ler a produção textual antropológica no interior de uma tradição livresca fundamental para a construção do seu público-leitor.

Apesar de reconhecermos protocolos de leitura que estão na base na produção textual antropológica, em muitos destes escritos quando o texto passa de um nível de circulação doméstica, para o de publicação impressa, inúmeras vezes, a decisão do editor por este ou aquele título, sub-titulo, seqüência de imagens, etc. se dá menos em razão do campo acadêmico e mais do lado comercial da obra, no sentido de tornar sua leitura menos "virtuosistica", nos termos de R. CHARTIER (1996). Não estamos nos referindo ao aprisionamento da competência da tradição da produção textual antropológica às práticas de mercado, ainda que isto poderia ser uma fonte fecunda de pesquisa.

No interior das práticas políticas da escrita, encontram-se políticas de leitura. Neste sentido, a produção textual dos antropólogos não esta livre de toda e qualquer lógica das produções culturais, mesmo que não se reduza a ela. O que esta em jogo, por exemplo, no título atribuído por uma editora a uma obra produzida pelo antropólogo? Podem ser as possibilidades de markentig oferecido por seus escritos em função de instigar o leitor potencial, de colocá-lo a par do texto que o espera? Vejamos a obra de Marcel Mauss, Essai sur le don, forme et raison de l'échange dans les société primitives, artigo originalmente publicado no Année Sociologique, segunda série, com data de 1923-1924, e o mesmo artigo compondo uma nova edição, publicada anos mais tarde, em 1950, pela Presse Universitaire Française (PUF) com o título Sociologie e Anthropologie, com o prefácio de C. LÉVI-STRAUSS. Uma introdução que fará com que nunca mais a obra de Marcel Mauss possa ser lida ingenuamente, pois influenciou, e continuará influenciando, as formas de ler a obra de M. MAUSS por toda uma geração de antropólogos.

Neste mesmo contexto, podemos pensar os efeitos das decisões dos editores por tal ou qual design das páginas na publicação de uma obra escrita por um antropólogo, anunciando ou sugerindo ao seu futuro leitor. Outro exemplo: a primeira edição do livro de G. Durand, Science de l'homme et tradition, "le nouvel esprit anthropologique", de 1979, pela Berg International e a edição de Albin Michel, em 1996. Na primeira edição, que faz parte de uma coleção dirigida pelo próprio autor, 1'Ile Vert, em alusão à filiação do autor às utopias fundadoras e criadoras da imaginação humana, a capa traz a reprodução da figura de Hermes Trimegistus contemporaneus, 
que se encontra na catedral de Siena, o sub-título situa-se na folha de rosto, e abre o espaço livresco, junto com as escritas do autor, localizadas nas "orelhas", tendo, junto com ela, a Table de matières à frente como guias de leitura. A leitura da obra original é já um convite à decifração de seus múltiplos planos narrativos. ${ }^{3}$

Em contrapartida, a edição mais recente, esta forma adota um sentido editorial outro, menos esotérico e mais exotérico. Ela agora faz parte explicita de uma coleção La pensée et le Sacré: seu subtítulo, que antes se insinuava na abertura do espaço livresco, encontra-se aberto a todos na capa, e onde, agora, temos a reprodução da imagem do quadro de Vermeer de Deft, do séc. XVII, L’Astronome, exposto no Musée du Louvre, em Paris. A contracapa para um olhar desavisado pode parecer a mesma, mas não. Embora contenha os mesmos escritos do autor sobre a crise nas ciências humanas ${ }^{3}$ acrescenta-se a eles os títulos honoríficos do autor, indicando outra de suas obras no interior desta mesma coleção. Tudo aquilo que estava escrito nas orelhas da antiga publicação sobre o arquipélago do imaginário e suas ilhas, em alusão ao trabalho dos poetas, dos pintores, dos músicos, linhagem na qual G. DURAND inclui os próprios antropólogos, perderam-se na poeira do tempo editorial. Certamente, o título e a presença de imagens, as mais diversas, dentro das páginas tanto quanto o formato doa textos em ambas as ocasiões foram estrategicamente formuladas pelas editoras como forma de desencadear no seu leitor um determinado processo de leitura, ao convocá-lo a traduzir a cultura de um determinado grupo, por exemplo, a partir do cruzamento de várias linguagens visuais contidas num mesmo espaço livresco.

Entretanto, pode-se perceber claramente quando num caso o autor torna-se ele próprio editor de seu texto e quando a primeira figura esta abandonada à sorte da figura do editor. No caso de ambas as publicações, nós podemos constatar os recursos estilísticos que valorizam o texto etnográfico, e que foram exploradas pelo antropólogo e re-inventadas pelas editoras, e que acabam por criar a tão desejada "distância etnográfica" - colocando o leitor dentro dos fatos ocorridos, ou anulando o mal estar da alteridade - fazendo-o tomar consciência do espaço textual e livresco. Assim há práticas políticas na escrita etnográfica tanto quanto nas suas múltiplas leituras, uma particularidade do mercado livresco que mesmo a Antropologia, literatura ou ciência, não pode prescindir para a sua existência, ainda que a tradição de sua produção textual não se limite a ele.

Aplicando-se, assim, alguns princípios estudados pelos historiadores da cultura, pode-se constatar que o debate em torno da autoridade etnográfica e da função-autor nos escritos

\footnotetext{
3 A crise das ciências humanas de que trata esta obra de G. DURAND é a mesma que conduziu, no fim dos anos 60, to autor em reação ao estruturalismo e ao marxismo, e que iria conduzir M. FOUCAULT, nos anos 70, a encerrar a figura do autor nas praticas discursivas inscritas em práticas institucionais.
} 
antropológicos não pode prescindir do debate em torno do conjunto dos condicionamentos editoriais que atuam no processo produção do texto etnográfico, pois dele depende as formas particulares nas quais o leitor, erudito ou não, é posto diante "do olhar, da leitura e da audição" da produção de conhecimento antropológica e onde estão em jogo "as competências, convenções, códigos próprios à comunidade a qual pertence cada leitor” (CHARTIER 1999: 19). A escrita etnográfica esta associada às condições históricas de determinadas práticas de leituras e ao surgimento do homem das letras. Da mesma forma, as produções textuais de conhecimento na Antropologia relacionam-se ao surgimento da figura do escritor-tipógrafo e do humanista, em pleno séc. XVI, em seu papel de fazer respirar a letra morta, de distribuir o sentido das palavras escritas e distinguir seus graus diferentes de subordinação pela forma modulam-se e adaptam-se os seus signos mudos a todo um sistema complexo de pontuação. Com estas observações queremos chamar atenção para o fato do quanto ao se ler a produção de conhecimento antropológica estamos apreendendo as suas modalidade de escrita, ainda que implicitamente, sem que se processe uma reflexão mais sistemática sobre a combinação entre tais elementos do “codex" da obra etnográfica e o papel narrativo que eles assumem na exposição dos acontecimentos narrados pelo antropólogo na sua produção textual.

Tal qual o que aludimos nos dois casos aqui apontados, o da introdução à obra de Marcel MAUSS, por C. LÉVI-STRAUSS e das duas edições da obra de G. DURAND,Science de l'homme et tradition, se nos detivermos nos modelos adotados para as publicações das obras dos antropólogos que costumamos ler, vamos observar que os títulos e os sub-títulos adotados na obra, os usos diferenciados dos fragmentos de testemunhos, diálogos e/ou depoimentos no seu interior, na forma que estes fragmentos tornam a leitura do texto descontínua, apontam para o prazer da leitura segundo a alternância entre blocos compactos e passagens mais leves.

Aprofundando-nos ainda mais neste detalhamento da construção textual que subjaz as modalidades de escrita do pensamento antropológico, se observarmos, nos distintos momentos da narração, às marcas das passagens entre o narrado ao dialogado, um recurso tipográfico que auxilia o leitor na leitura da página, e que lhe antecipa as modulações no interior de uma mesma narrativa; se prestarmos atenção às múltiplas escalas de proposições descritivas daquilo que é narrado pelo antropólogo, segundo os seus deslocamentos no espaço e suas sucessões no tempo e se atentarmos para as formas de escritas adotadas que buscam restaurar os atos performáticos da língua falada pelo "nativo" tais como sotaques, entonações e intensidades, tanto quanto a escolha da fonte e o trabalho sobre a imagem da letra que, pelo desenho das mesmas pode ser utilizada pelo autor como sugestão de uma "narrativa-caligrafia" ou se uma escrita "de época", etc, 
poderemos constatar as formas gráficas adotadas pelo conhecimento antropológico quando este habita o espaço livresco.

\section{Invenção e tradição: a intertextualidade na produção da unidade textual do conhecimento antropológico}

De um ponto de vista mais operatório, gostaríamos de apontar para a intertextualidade ${ }^{4}$ na produção escrita do pensamento antropológico e que coloca toda a produção textual deste campo de conhecimento como resultado da cooperação entre textos produzidos por outros antropólogos, que se interpenetram, dando origem, as outras formas de pensar em Antropologia e que, inclusive, modificam os precedentes. Uma obra de C. LEVI-STRAUSS (1975), Anthropologie Structurale, pode ser aqui citada como paradigmática deste fenômeno. Antropologia estrutural é uma obra na qual este autor fazer emergir o próprio campo de conceitos da Antropologia do interior das produções textuais de inúmeros antropólogos nela reunidos. O capitulo I desta obra, Histoire et Etnologie, ao mesmo tempo Introdução, trata do dialogo deste autor com a produção textual, na língua de origem, de alguns de seus colegas, evolucionistas clássicos como E.B.TYLOR (Primitive culture, 1871), funcionalistas como B.MALINOWSKI (The sexual life of savage in North-Western Melanésia,1929; Sex anda repression in savage society, 1927, Culture as a determinant behavior, 1937, etc.) e do pai fundador da escola histórica em Antropologia, F. BOAS ( The social organization and the secret societies of Kwakiutl indians, 1895; Methods of ethnology, 1920; Evolution or Diffusion, 1924, etc ) além de A.L. KROBER (History and Science in Anthropology, 1935, etc. ), e dos seus mestres de tradição intelectualista 5 , E. DURHEIM et M. MAUSS (De quelques formes primitives de classification, 1902) entre outros, na firme tentativa de fundar os limites epistemológicos do conceito de estrutura no estudo dos fenômenos da cultura.

$\mathrm{Na}$ seqüência desta obra, os capítulos II, L'analyse strcuturale em linguistique et em anthropologie, III, Langage et société, IV, Linguistique et société, e V, na forma de um post-facio aos capítulos III e IV, que configuram a Parte Langage et Parenté, revisitam as teorias de lingüistas clássicos como F. de SAUSSURE (Cours de Linguistique, 1916) e R. JACOBSON (Remarques sur l'évolution phonologique du russe, 1929) e de alguns estudos clássicos de parentesco promovidos seja por representantes da escola estrutura l-funcionalista como

4 Cf. G. GENETTE, Palimpsestes, la littérature en second degré. Paris, Seuil, 1982, 7-14.

5 Expressão cunhada por RC CARDOSO DE OLIVEIRA, Sobre o pensamento antropológico. Rio de Janeiro, Tempo Brasileiro, 1997. 
RADCLIFE-BROWN (The mother's brother in South Africa, 1924, The study of kinship systms, 1941, etc.), ou de alguns herdeiros da escola histórica R. BENNDICT (Tibetan and chinese kinship terms, 1942, Studies in Tahi kinship terminology, 1943) E A. L. KROBER (Classificatoy systems of relationship, 1909, The societies of primitive man, 1942, etc.) para criar as bases da análise estrutural em Antropologia. Na sequiência destes capítulos podemos identificar um laborioso projeto intelectual que se desdobra em análises pontuais de fenômenos da cultura a partir de seu detalhamento teórico-conceitual - sociedades primitivas, mitos, estruturas de parentesco, sistemas de organização social, etc.- onde se pode observar a luta de um antropólogo por constituir seu lugar de autor a partir da fundação de uma determinada discursividade, algo que ele deverá revelar sua potencialidade explicativa por ele sustentada, nos capítulos posteriores

Com a publicação de Anthropologie Structurale, pela discursividade singular que elainstaura, conjuntamente as outras obras de C. LEVI-STRAUSS, nas formas de produção de conhecimento em Antropologia, podemos constatar que o nome deste autor irá assegurar, desde aí, uma função classificatória na produção textual antropológica, ao permitir agrupar, em torno dele, um certo numero de textos produzidos por outros antropólogos, diferenciados imediatamente, a partir de seus traços temáticos e formais, de outros conjuntos de produções escritas desta matriz disciplinar.

Ao observarmos, portanto, o nome dado a esta publicação podemos constatar a importância inaugural atribuída a esta uma obra Anthropologie Structurale- ainda que se constate que ela reune, em capítulos, inúmeros artigos escritos por C. LEVI-STRAUSS ao longo de sua atuação acadêmica, artigos que foram publicados anteriormente em inúmeras revistas de renome internacional (World Journal of the Linguistic Circle of New York, Amercian Anthropologist, Revue de Métaphysique et de Moral, etc.), e que reunidos, na época, sob a denominação fundacional de Anthropologie Structurale, revela um cuidadoso processo de produção textual onde se pode ver o autor C. LÉVI-STRAUSS consolidar sua autoridade sob o tecido de uma argumentação que, hoje, já se tornou um clássico na tradição de pensamento antropológico. Um exemplo claro do que aponta M. Foucault para a função-autor no coração da produção textual em Antropologia, ou seja, o antropólogo como autor existe em relação à função atribuída a um certo tipo de texto em determinadas práticas institucionais que define para um tal texto certos usos específicos.

O que une, então o nome de C. LÉVI-STRAUSS aos seus textos ? O fato de que eles, desde a publicação de Anthropologie Structurale, se tornam parte constitutiva do próprio nome de seu autor, ele próprio, a origem, a garantia e o proprietário da análise estrutural nos estudos 
antropológicos, dotando estas análises de um status específico. Ao referir na sua produção textual a produção textual de outros antropólogos, cumulativamente, C. Lévi-Strauss, acabou por validar sua propria discursividade no interior de outras discursividades fundadoras do campo de conhecimento antropológico. Neste sentido, a publicação desta obra, uma reunião de artigos contendo uma série dispersas de operações de pensamento de sua autoria, resultam na formação de uma réplica de tais operações, agora na forma de uma obra formatada nos moldes clássicos exigidos pelo cultura da escrita - o espaço livresco. Neste sentido, o leitor passa a reconhecer na obra, Anthropologie Structurale, uma unidade estilistica singular e uma coerência conceitual e teórica que de outra forma seria impossível.

Por outro lado, na "tela de fundo" das páginas deste livro, Anthropologie Structurale, desvela-se para o leitor- antropologo mais atento toda a imensidão de obras, idéias e pensamentos de sobre as culturas e sociedades humanas que fazem parte da tradição da cultura antropológica. Ao mesmo tempo, Anthropologie structurale nos revela a forma como se funda a autoria e a autoridade do pensamento estruturalista levistrausssiano, um dos maiores expoentes ainda vivo tradição do pensamento antropológico contemporâneo.

Adentrando as características da produção textual que originou este objeto-livro levistraussiano, vale se ressaltar as formas diferenciadas de intertextualidade que funda Anthropologie structurale, ou seja, sua atribuição de obra que nasce na relação com outras produções escritas no campo das diferentes tradições de pensamento que fundam matriz disciplinar da Antropologia que de alguma forma se encontram presentes na tessitura da trama conceitual que autoriza a análise estrutural de C. LEVIS-STRAUS no seu interior Trata-se de uma produção textual engendrada por outros tantos textos escritos por antropólogos, anteriores a esta obra e que por transformação de seu conteúdo de origem, através de formas diversas de seqüências associativas entre suas produções textuais, com base em relações não lineares entre seus componentes, e segundo suas especificidades, acabam por constituir-se parte integrante da obra em si.

Sob o enfoque da intertextualidade os escritos antropológicos resultariam, então, do cruzamento de estilos e tipos de texto (J.KRISTEVA 1969: 144-145), da imanência mesma da linguagem no texto e que se expressa no plano interior da poética do tecido textual que cria a obra (R. BARTHES, ) ou da referência ao dialogismo de todas as formas que fundam as relações entre os estilos de textos e a linguagem da própria sociedade, ou, ainda, entre um texto e seu destinatário ou, ainda mais, no caso da literatura, entre a subjetividade do narrador e a consciência de seu personagem (M. BAKTIN 1978:222-225). 
Observar, neste sentido, as múltiplas práticas de escrita da qual se nutre o conhecimento antropológico desde sua fundação, torna-se uma forma possível de ser refletir sobre a aventura intelectual que encerra a construção sua autoria textual. Neste ponto, como afirma J. RANCIÈRE (1995), nem mesmo os antropólogos estão livres da orfandade que conforma o corpo da letra, pois o sentido de sua escrita, como bem se pode ver na publicação da obra Anthropologie Structurale, só existe através dos textos que ela recompõe no interior da própria tessitura que sustenta o ato de escrever. Isto significa aceitar que qualquer narrativa etnográfica se configura não apenas a partir de causas exteriores (do mundo, do autor e de suas influências), mas também da forma como os textos escritos pelos antropólogos se relacionam entre si, se transformam, se assimilam ou se dispersam segundo seus diversos procedimentos narrativos, desde as relações de inclusão entre um texto e outro, para o caso de citação, e mesmo relações de derivação entre eles.

Se fora do realismo das formas representacionais pretendidas pelo texto etnográfico, e na trilha da busca de um texto dialógico, o que se encontra é sempre sua referência a outros textos, a intertextualidade poderia vir a confirmar a morte do antropólogo como autor, pois este acabaria prisioneiro da lógica de sua produção textual que produz a sua lisibilidade. Neste contexto, restaria, finalmente, se aceitar que o texto etnográfico desfruta deste status não por estar referido ao mundo dos fatos, mas ao processo de produção textual e suas normas socialmente compartilhadas. Nesta perspectiva, na escrita etnográfica a citação do pensamento de um outro antropólogo ou mesmo da transcrição da fala de um "nativo", geralmente entre aspas, se caracteriza pela presença evidente de um texto estrangeiro ao do próprio autor, geralmente indicado, explicitamente, por ele a sua origem, e através do qual ele o integra a lógica do seu texto, ou pelo menos de seu autor.

Trata-se aqui de um procedimento que é usual na escrita antropológica de teses, dissertações, artigos, revistas e livros, etc. O texto citado pode aparecer literalmente dentro texto, mas pode ser apenas mencionado ou aludido. No primeiro o que predomina é a idéia de colagem, que insistem sobre o caráter de descontinuidade entre ambos os textos; no segundo caso, no respeito à continuidade, opera-se com a unidade do fluxo narrativo (incluindo-se ai, uma citação diluída no texto, mas assinalada em outro lugar, por exemplo, em nota de rodapé), ou seja,predomina a idéia de integração entre todos os textos. Há, entretanto, a possibilidade de existência de um terceiro tipo de relação de hipertextualidade que resulta do cruzamento de textos através de uma tentativa de atualização de um texto primeiro em outro. Como mencionado logo acima, a co-presença de um texto em outro pode ou não se mencionada, integrando ou não o texto que o convocou, entretanto, sob uma forma ou outra, uma tal intertextualidade acaba 
atribuindo autoridade etnográfica à escrita do antropólogo, como se pretende aprofundar na seqüência deste artigo:

\section{O dentro e o fora do texto etno-gráfico e as políticas de escritas em Antropologia}

Estas observações, inspiradas nos estudos de textos literários, por um lado, e nos estudos de historiadores das praticas da leitura e da escrita nas sociedades humanas, por outro, são provocativas, pois nos auxiliam na reflexão acerca do texto etnográfico clássico e de suas condições de inteligibilidade, seja na ambiência acadêmica, seja fora dela, na WEB (que é o nosso caso).

A escrita como simples re-transcrição ou imitação do oral (prisioneira do jogo combinatório linear das palavras e de seu fluxo irreversível), sem nenhum espaço em branco e sem pontuação, e cujo suporte era o volumen, um rolo que se desenrolava à medida que o texto era lido; a escrita revista a partir da invenção do codex, onde o texto projetado na superfície de uma pagina, ganha autonomia em relação à oralidade, transformando-se em espaço de leitura; a escrita recriada a invenção da imprensa e do livro moderno, em que o texto sofistica-se como espaço de leitura através da sua expressão em termos de signos de pontuação, separação das idéias em parágrafos, numeração de paginas, índices e index, das referencias cruzadas, etc., como se podemos registrar, a formatação do espaço da pagina contribui para a formação do sentido do que é escrito até mesmo para a produção textual dos antropólogos que não se encontram fora destas determinações do espaço livresco.

Estas observações nos permitiram até aqui compreender os múltiplos dispositivos que estão na base da construção textual da verdade do conhecimento antropológico, tomando-se, aqui no caso, as influências do espaço livresco na construção das suas formas de pensamento.Obviamente que para além das convenções literárias que cercam as operações textuais nas quais esta mergulhada a produção escrita do pensamento antropológico e da qual se origina a construção da autoridade do antropólogo, tais operações textuais, entretanto, remetem a problemas que vão além das "micropráticas" discursivas implantadas pelas instituições acadêmicas. Trata-se agora de outro desafio: pensar a escrita etnográfica tendo por base o fato de que através de que ela resulta da incompletude presente nas relações entre a letra morta, muda e falante, e a palavra viva. Nas praticas discursivas institucionais dos cursos de pós-graduação advoga-se a importância de se ensinar aos neófitos às técnicas e procedimentos da pesquisa antropológica, entretanto, esquecemos de lhes ensinar a escrever "antropologicamente" como parte decorrentedas aprendizagens do método etnográfico. Entretanto, todos nós professores sabemos que nossos 
aprendizes de antropólogos aprendem a escrever suas etnografias na medida em que se tornam leitores acurados de uma extensa bibliografia resultante de uma tradição de escritos de antropológicos: ensaios, monografias, livros, etc. Ou seja, aprende-se conceitos e teorias do campo da Antropologia ao mesmo tempo em que se aprender a escrever e ler "etnograficamente" uma cultura no esforço de transpô-la para a superfície da folha de papel na captura daquilo que nos foi dito pelo outro e que compartilhamos com o outro. Seguindo P. RICOEUR, a figura do leitor aqui é imprescindível para que se possa compreende a complexidade que preside as aprendizagens do ofício de antropólogo, em especial para a escrita textos etnográficos.

De acordo com o autor, não se pode escrever um texto como quem o lê, da mesma forma como não se pode lê um texto, por mais simples que ele seja, da mesma forma que quem escreve. A leitura trata de um dialogo com a obra escrita, ela lhe interroga o sentido, lhe coloca questões, lhe exige respostas. Ler e escrever, dois atos fundamentais, complementares do ouvir e do ver, de naturezas distintas, mas de mesma ordem de grandeza na formação do antropólogo. Parafraseando este autor, todo a autoria do texto oculta, em si mesmo, a figura do escritor e a sua voz tanto quanto a figura do leitor e os seus ouvidos. Assim, aprender a pensar o mundo através da matriz disciplinar da Antropologia, portanto, não esta fora das aprendizagens das operações textuais e linguísticas através da qual uma experiência de campo se torna obra escrita (geralmente inspirada na forma de objeto-livro impresso).

Não só se aprende a fazer antropologia na alteridade dada pela marca da oralidade e a corporalidade da experiência do trabalho de campo, como esta alteridade é mais fortemente percebida no momento em que as exigências da produção textual se apresentam. A prática da escrita atribui consistência temporal e densidade de consciência aos embates do antropólogo no interior do processo de construção de sua identidade narrativa diante do deslocamento da palavra viva, sua e do outro, tornada, agora, letra morta.

Inspirando-nos em DE CERTEAU, a palavra escrita instituída no lugar da palavra viva, destinada a ser ouvida fora do seu lugar de enunciação, é deste lugar que trata o caráter trágico de toda e qualquer aprendizagem do ser etnógrafo e que toma a produção textual como condição inalienável de acesso a tradição do conhecimento em Antropologia.

Por outro lado, no processo de produção textual do conhecimento antropológico esta presente um fenômeno que perpassa toda e qualquer criação literária, ou seja, o dos deslocamentos constantes entre as práticas de leitura e da escrita. Entretanto, diferente da criação literária tais deslocamentos se constituem como parte integrante da consolidação da figura do antropólogoautor se tais operações permitem que a escrita percorra a palavra viva do outro e saiba o que ela diz, e que reconheça a sua forma diferente de fala 
O que se encontra fora da palavra escrita e que precisa por ela ser acessado, ou aludido, ou capturado, ou revelado, ou re-presentificado para que a letra morta possa sair de seu mutismo e torna-se, enfim, falante? O que se torna necessário nas políticas da escrita antropológica para que o corpo da letra descubra seu corpo de verdade? A produção textual dos antropólogos está endereça a uma palavra ausente, tanto a minha quanto à do outro, não posso resolver burocraticamente esta questão, esta aí a inquietação do corpo da letra, e ela é necessária a prática da produção de conhecimento antropológico, insubstituível na sua singularidade, como qualquer outra forma de expressão do pensamento antropológico (vídeo, filme, fotografia, áudio).

Conforme afirma DE CERTEAU, na reprodução escrituraria, as diferenças entre "eles" e “ "nós" põem em causa uma relação de poder pois afirma verdades que se tornam não-perecíveis mas que tão logo foram enunciadas se diluíram no tempo. pois uma escrita ao mesmo tempo que estudamos textos de outros antropólogos nós os produzimos cotidianamente em nossa prática profissional. Da mesma forma, os trabalhos escritos pelos antropólogos revelam as diferenças entre "nós" e "nós mesmos", a tribo dos antropólogos, e entre eu e o "mim mesmo" pois me relaciono através dos textos com meus antepassados através dos vestígios deixados por eles nas folhas de papel, posteriormente consumido na forma de um livro, e impresso por uma cada editorial qualquer. Num e noutro caso, permanece lá tudo aquilo que a letra morta não conseguiu registrar, ainda que, ao ser lida, sua voz possa revelar a respeito do lugar de onde escrevia que só permitia ver aquilo que ali se encontra registrado, que circunscrevia meu olhar, meus ouvidos, meu corpo quando ali estava quando as palavras foram pronunciadas, os gestos realizados, as ações executadas.

Sem dúvida, gostaríamos de ressaltar o que De CERTEAU comenta, RANCIÈRE retoma e P. RICOEUR desenvolve, ou sejam de que é no ato da escrita que o buraco do tempo se revela, pois é no corpo nu da letra morta, muda e falante, e, acima de tudo órfã, que se coloca o problema da ausência de sentido do que foi pronunciado. Estamos aqui em pleno tema da memória (a escrita invade o espaço e capitaliza o tempo ${ }^{6}$ ), pois a produção textual dos antropólogos, em especial nos referimos a produção de escritos etnográficos, embora aluda as lembranças do outro ouvidas, vividas observadas no trabalho de campo, logo a tudo aquilo que esta fora do texto, produz, através da leitura do próprio texto, um retorno, "de si para si", pela mediação do outro. Na hermenêutica do outro o perigo de se cair apenas na etnografia de si-mesmo.

Quando falamos modernamente na repartição do lá (o mundo do outro) e do aqui(omundo do antropólogo), na separação do que esta fora e o que se situa dentro do texto etnográfico, na

6 CF. M. DE CERTEAU ( : 217) 
momento em que a letra muda se torna falante para o próprio antropólogo-autor que estas diferenças estruturais no espaço da escrita, com o desenrolar da própria narrativa etnográfica, começam a se embaralham, revelando-lhe uma espessura inaudita para a sua escrita. É momento em que todos nós ao escrevermos nossas etno-grafias nos damos conta de que a escrita de uma cultura supera o próprio registro das idéias através dos signos gráficos numa folha de papel pois ela é puro relato (récit), esta escrita que se mescla a um olhar científico constrói uma representação de mundo, imagens concebidas do outro, e construídas por mim. Não há, neste momento, como não se inquietar diante da possível lineridade do sentido por mim enunciado sobre e do espaço por mim construído para sua vida, do abismo que nos separa..

É preciso que se diga que precisamos contar com o movimento do pensamento, seu desdobramento no tempo, através do ato de virar as páginas escritas, como fenômeno capaz de produzir uma alteração no interior do texto, no sentido de revelar o deslocamento do si-mesmo do antropólogo pelo lugar do outro que ele agora representa como condição de existência para seu próprio conhecimento. Antes de tentar acomodar a perturbação que o corpo da letra revela da produção textual etno-gráfica, para DE CERTEAU ( ), esta escrita funciona precisamente por que ela mantém intacta à distancia de sua relação com o seu lugar de produção.

Em nossas aulas de Antropologia, desafiar o neófito a refletir sobre este tema, portanto, lhe permitiria ter consciência de que é também em função de um sistema de textos que dão sustentação ao seu ofício, tanto quanto a sua relação ao mundo real do "nativo", que qualquer texto etnográfico produzido por um antropólogo pode ser lido e compreendido por outro. Neste sentido, não só a intertextualidade, torna-se parte da condição de legibilidade da autoridade etnográfica uma vez que é através dela que o antropólogo pode associar o sentido dos dados e das informações colhidas por ele durante o seu trabalho de campo a partir dos lugares do texto onde aparecem como referencia ao mundo real dos fatos. $\mathrm{Na}$ aparente falta ou ausência de sentido presente à palavra viva do outro e na sua condição de passagem para o sentido, dado através da palavra escrita, traduzida pela letra órfã, na falta seu corpo, é que o oficio de antropólogo se inicia, como promessa de expressão do seu encontro com o outro.

\section{Os desafios da leitura e da escrita de um hipertexto etnográfico}

No processo de construção das coleções etnográficas a serem disponibilzidas na base de dados do BIEV(BIEV-data) e na web, através do site www.portoalegre.ufrgs.br (BIEV-site), temos visto que esta nova forma de organização dos saberes a partir de sua numerização, não 
mais localizados num espaço concreto, modifica o estatuto do texto etnográfico que tem como referencia o objeto-livro, separando a produção textual do seu suporte original. No caso da criação de novas escritas etnográficas em hipertexto, por exemplo, temos visto que há todo um extenso trabalho de definição da natureza dos laços entre os dados etnográficos, as informações que de que portadores, do conteúdo de seus laços com outros documentos colocados num mesmo ambiente de consulta e da estrutura que se montam segundo as escolhas de percurso que sua utilização permite ao usuário-leitor.

Estas observações a respeito da escrita e da leitura de um documento etnográfico segundo as praticas enunciativas hipertextuais as quais comportam a manipulação de dados etnográficos de sistemas culturais dos quais o usuário desconhece o sistema de origem, isto é, de onde tais informações provêem, coadunam-se com os comentários de Jean CLEMENT (2000) a respeito de que a noção de hipertexto contempla as noções de ruído, sistema e caos.

Uma dimensão importante das textualidades eletrônicas que obriga todo o antropólogo a refletir sobre as condições que cercam as operações de produção de uma etnografia em hipertexto ou hipermídia e a característica sistêmica que é inerente a este tipo de documento. Ou seja, o relato etnográfico não pode mais se transmitir apoiado na linearidade das informações dispostas uma após a outra, característica do texto escrito, mas de informações associadas a determinadas ações de consulta a uma base de dados.

A partir do estudo das novas textualidades eletrônicas que preside a criação de documentos etnográficos tendo como suporte do pensamento antropológico com base nas tecnologias das informáticas e dirigidas às redes digitais e eletrônicas, este artigo investe em uma reflexão mais detalhada a respeito do estatuto da representação etnográfica no âmbito dos saberes antropológicos. Neste sentido, vale-se de alguns apontamentos recolhidos dos estudos sobre o tema da intertextualidade na literatura e aqui aplicados ao campo da produção de conhecimento em Antropologia.

Como referido anteriormente, a leitura de uma narrativa escrita se atualiza tradicionalmente nas páginas de um livro-objeto, entretanto, no espaço das novas praticas enunciativas hipertextuais, a leitura desenrola-se como nos antigos rolos, e agregando a esta modalidade se oferece ao leitor em diferentes formas de manipulação, segundo seus caprichos pessoais. No caso do BIEV, como se verá a seguir, a narrativa escrita se concentra no espaço interno de uma citação, curta ou longa, onde o tempo e o ritmo da leitura já foi dirigido pelo pesquisador antes do próprio leitor ter acesso ao texto.

Tendo em vista que são os dados de campo da investigação etnográfica aqueles estamos disponibilizando nas redes eletrônicas e digitais, a pesquisa do BIEV vem tratando, ainda que 
indiretamente, do tema bastante atual do direito de propriedade, por parte do antropólogo, de um patrimônio não material recolhido por ele junto a uma determinada população e do qual resultou produção/reprodução/criação de suas imagens, segundo suportes diversos (fotográficos, textuais, filmicos ou sonoros), expostas na rede mundial de computadores. Diante destes desafios de restauração da palavra do Outro, a emergência de uma etnografia hipertextual no âmbito do Banco de Imagens e Efeitos Visuais tem nos conduzido a refletir sobre os princípios éticos que orientam o saber-fazer antropológico tradicionalmente produzido na forma de objeto-livro quando ele é confrontado não somente aos desafios de se romper um discurso hegemônico sobre o Outro, orientado que esta pela defesa da igualdade dos grupos humanos na diferença, mas quando se projeta na rede mundial de computadores, na era das textualidades eletrônicas.

Cabe salientar que não se trata, neste artigo, de afirmar a morte do leitor e do livro, e mesmo cinema e do filme etnográficos diante das novas formas de comunicação eletrônica. De uma forma ou outra, conforme já se sustentou em outras publicações ${ }^{7}$, a cultura da tela ${ }^{8}$ e civilização da imagem propõe novas formas de re-organização dos saberes que os outros suportes mais tradicionais disponibilizam, transfigurando seu sentido original e lhes atribuindo uma significação mais móvel, plural e instável pelo caráter granular que atribui a todos eles.

Diante do ambiente hipertextual desterritorializado, a existência das antigas práticas de escrituras de que são portadores os antropólogos tanto quanto os micro-territórios de suas obras etnográficas lhe atribuem o status de autores sofrem novos constrangimentos, agora nos termos que alguns chegam a denominar de engenharia autoral, isto é, com base na geração e manipulação de informações e dados digitais segundo modelos de suas configurações visuais (letras, palavras, textos) em arquivos registrados e transportados segundo determinados procedimentos de montagem e associação de idéias e que conta com o leitor como co-autor.

Ainda que preexista esta engenharia do texto ${ }^{9}$, num hipertexto o leitor desfruta de uma autoridade compartilhada com aquele que o produziu, segundo sua competência em hierarquizar, classificar e unificar uma gama infinita de informações e dados que cobrem semelhante obra,incluindo-se ai o risco, inclusive, de destruí-la.

7 Cf. artigos publicados ECKERT, C. E ROCHA, A.L.C. da , A cidade, o Tempo e a Experiência de um museu virutal : pesquisa antropocronotopológica nas novas tecnologias, In : Campos - Revista de Antropologia Social, Edições do PPG Antropologia Social/UFPR, ano 2002, Vol. 2 e ROCHA, A.L.C. da, Tecnologias audiovisuais na cosntrução de narrativas etnográficas, um percurso de investigação, In : Campos - Revista de Antropologia Social, Edições do PPG Antropologia Social/UFPR, ano 2003, Vol. 4. Todos os dois artigos disponíveis no site www.estacaoportoalegre.ufrgs.br.

8 A próposito ver o artigo por nós produzido, ECKERT, C. E ROCHA, A.L.C. da, "Escrituras Hipermidiáticas e as Metamorfoses da Escrita Etnográfica no Banco de Imagens e Efeitos Visuais". In: Iluminuras, Série do Banco de Imagens e Efeitos Visuais, número 63. Porto Alegre: BIEV, PPGAS/UFRGS, 2004.

9 Aplica-se aqui este termo empregado por O.ERTZCHEID, no artigo Pratiques énnonciatives hypertextualles :Vers de nouvelles organizations mémorielles, abril de 2003, In : http://archee.qc.ca/index.ht, consulta em dezembro de 2003. 
Nos termos de J. CLEMENT (2004) o processo de numerização de documentos etnográficos além de conduzir à desmaterialização de tais suportes específicos, por sua natureza rompe com o sistema hierarquizado de leitura do objeto-livro, ao propor, por seu caráter elíptico, a leitura de dados e informações com base na "deslinearização do discurso narrativo autoral e a por sua relinearização a partir de um leitor singular", ainda que o autor guarde ainda a prerrogativa do ordenamento das suas unidades narrativas pois é ele que fornece os laços que unem tais dados.

Neste sentido, ao se pensar a produção de ums etnografia em ambiente hipertextual, não se pode operar na figura clássica do leitor e dos atos de leitura de uma obra etnográfica clássica (em formato de objeto- livro) onde se pode, num dia, iniciar a leitura do primeiro capitulo, parar, e num outro, retomar a sua leitura exatamente do ponto de onde se estava, deslocando-se, caso se deseje, até o capitulo final, para retornar ao ponto inicial, e continuando a ler o primeiro capitulo. Rompendo-se o laço original que une o autor à sua obra tanto quanto a natureza dos laços que a unem ao seu leitor, a escrita antropológica é interpelada pelos percursos dos laços hipertextuais adotados pelo leitor-navegador; ainda que o autor guarde para si a prerrogativa dos trajetos a ele oferecidos. E importante se ressaltar a busca de um certo tipo de semantismo dos laços que unem os documentos etnográficos entre si, segundo os tipos de relações entre eles. Isto é, os documentos etnográficos ao adotarem um lugar no interior de uma coleção etnográfica, em sua diversidade de suportes (vídeo, som, texto e foto) não detêm nenhum tipo de exclusividade em termos de sua composição e arranjo no interior das coleções, obedecendo a laços editados por todo aquele que trabalha na formação desta base de dados. Sem duvida, as bases de dados do BIEV propõe, diferencialmente ao seu leitor-navegador um certo suplemento de visibilidade das tipologias de laços entre os documentos, etnográficos.

\section{REFERENCIAS}

ANDERSON, Kevin Taylor Etnographic hypermedia- transcending thick descriptions, 1999. http://cc.joensuu.fi/sights/kevin.htm, site consultado em janeiro de 2004.

BAKTIN, M. Esthétique et théorie du roman. Paris, Gallimard, 1978.

BARTHES, Roland. 'Texte (theorie du)'. Encyclopaedia Universalis. http://www.universalisedu.com, site consultado em fevereiro de 2004.

BATESON, G \& MEAD, M. Balinese character. A photo analysis. New-York, Academy of Sciences, 1942

BENNEDICT, R. "Franz Boas as an etnologist." In: Franz Boas 1858-1942. In Memoirs of the American Anthropological Association, n0 61, 1943.

BENICHOU P. L'Écrivain et ses travaux. Paris, J. Corti, 1967.

BRUNN Alain L'Auteur. Paris, GF-Corpus, 2001.

BARTHES, R. Plaisir du texte. Paris, Le Seuil, 1973.

BARTHES, R. G. Genette, Figures III. Paris, Le Seuil, 1970.

BOAS, F. "History and Science in: Anthropology: a reply". In: American Anhtropology, n.s., Vol. 38, 1936..

BOAS, F. "The method of ethnology”. In. American Anhtropology, n.s., Vol. 22, 1920. 
CARDOSO DE OLIVEIRA, R. \& CARDOSO DE OLIVEIRA, L. R. Ensaios antropológicos sobre moral e ética. Biblioteca Tempo Universitário 99. Rio de Janeiro, Tempo Brasileiro,1996.

CARDOSO DE OLIVEIRA, r. Sobre o pensamento antropológico Tempo Brasileiro, 1997.

CHARTIER, Roger. Lecteur et lectures à l'âge de la textualité électronique. http://www.interdisciplines.org/defispublicationweb, site consultado em janeiro de 2004.

CHARTIER, Roger. A aventura do livro, do leitor ao navegador. Sao Paulo, UNESP

CHARTIER, Roger. Ecritures Multimédia : les mutations du texte. Cahiers du français contemporain, ENS Editions, $n^{\circ} 6$ Mai 2000

CLEMENT, Jean Du livre au texte. Les implications intellectuelles de l'édition électronique'. Sciences et techniques éducatives. Volume 5- $\mathrm{n}^{\circ}$ 1/19998 2.

CLEMENT, Jean. http://www.interdisciplines.org/defispublicationweb, site consultado em janeiro de 2004.

CLIFFORD, James. "Sobre la alegoria etnografica".In: CLIFFORD, James y MARCUS, George

E. (Eds). Retoricas de la Antropologia. Madrid, Serie Antropologia, Jucar Universidad,

CLIFFORD, James. "Sobre a autoridade etnográfica". In: A experiência etnográfica. Rio de

Janeiro, UFRJ, 1999.

DERRIDA, Jacques De la grammatologie. Paris, Minuit, 1967.

DURKHEIM, E. e Mauss, M. "De quelques formes primitives de classification”. In: L'Année sociologique, vol. VI, 1901-1902

ECKERT, C. E ROCHA, A.L.C. da, "Escrituras Hipermidiáticas e as Metamorfoses da Escrita Etnográfica no Banco de Imagens e Efeitos Visuais". In: Iluminuras, Série do Banco de Imagens e Efeitos Visuais, número 63. Porto Alegre: BIEV, PPGAS/UFRGS, 2004.

ECKERT, C. E ROCHA, A.L.C. da , A cidade, o Tempo e a Experiência de um museu virutal : pesquisa antropocronotopológica nas novas tecnologias, In : Campos - Revista de Antropologia Social, Edições do PPG Antropologia Social/UFPR, ano 2002, Vol. 2.

ETRSCHEID, Olivier. Pratiques énoncitavies hypertextuelles : Vers des nouvelles organisation mémorielles, http://archee.qc.ca/ar.php?page $=\mathrm{imp} \&$ no=201, site consultado em abril de 2004 .

GEERTZ, Clifford. A interpretação das culturas. Rio de Janeiro, LTC, 1989.

GEERTZ, Clifford. Obras e vidas. O antropólogo como autor.Rio de Janeiro, Editora UFRJ, 2003.

GENETTE, G. Palimpsestes, la littérature en second degré. Paris, Seuil, 1982.

GOODY, Jack. La raison graphique: la domestication de la pensée sauvage. Paris, Minuit, 1979.

HAVELOCK, E. A. A revolução da escrita na Grécia e suas conseqüências culturais. São

Paulo: EDUNESP, Rio de Janeiro: Paz e Terra, 1996.

JACOBSON, R. Kindersprache, Aphasie und allgemeine lautgesetze. Upsala, 1941.

KRISTEVA, Julia. Sémiotikè, recherche pour une sémanalyse. Paris, Seuil, 1969

KROEBER, A. L. History anda Science. In:American Anhtropology, n.s., Vol. 37, 1935..

LEROI-GOUHRAN, André. Le geste et la parole. Paris, Albain Michel, 1969.

LEVI-STRAUSS, C. Antropologia Estrutural. Rio de Janeiro, Tempo Brasileiro, 1975.

LEVI-STRAUSS, C. Estruturas elementares do parentesco. Petrópolis, Ed. Vozes, 1982.

MALINOWSKI, B. Argonautas do Pacífico Ocidental. São Paulo, Abril Cultural, Pensadores, Atica, 1976.

MALINOWSKI, B. Culture. In:Encyclopoedia of the social sciencies. New York, 1935, Vol.

IV., Africa, Vol. 12, 1939.

MALINOWSKI, B. "The present state of studies". In: Culture contact, Africa, Vol. 12, 1939. 
MEAD, M. Sex anda temperament in three primitive societies. New York, 1935.

MEAD, Margaret. (1975) 'Visual Anthropology in a Discipline of Words' in Principles of Visual Anthropology, Paul Hockings (ed.), Mouton Publishers.

MORIN, Edgar. Introduction à la pensée complexe. Paris, ESEF, 1990.

RABAU, S. L'intertextualité. Paris, GF Flammarion, 2002.

RADCLIFE-BORWN, A. R. "The mother's brother in South Africa". In: African Journal of Science, Vol.21, 1924.

RIFATERRE, M. La production du texte. Paris, Seuil, 1979.

ROCHA, A.L.C. da, « Tecnologias audiovisuais na cosntrução de narrativas etnográficas, um percurso de investigação », In : Campos - Revista de Antropologia Social, Edições do PPG Antropologia Social/UFPR, ano 2003, Vol. 4. Todos os dois artigos disponíveis no site www.estacaoportoalegre.ufrgs.br.

TRICOT, A. 'Chroniques « hypertextes et hipermedias »' 1945-1995. Paris, Bulletin d'Informatique Approfondie et Applications, 46, 21-38.

TYLOR, E.B. Researches into the early history of man-kind and the development of civilization. Londres, 1865 